\title{
Apparatus for the differential visual depth threshold and its determination in the hooded rat'
}

\author{
HAROLD R. BOOHER ${ }^{2}$ AND RICHARD D. WALK, \\ DEPARTMENT OF PSYCHOLOGY, GEORGE WASHINGTON \\ UNIVERSITY, Washington, D. C. 20006
}

A modification of the visual cliff is described that permits measurement of the differential visual depth threshold, the point of relative indifference in choice of the shallow side as compared to the deep side of the visual cliff as the deep side is brought closer to the glass. All illumination comes from below the glass to permit equal illumination on the two sides. An experiment with the hooded rat showed that its threshold for differential visual depth is with the deep side about 3-1/2 in. below the shallow side of the visual cliff.

The usual visual cliff experiment places an animal on a center board with a "shallow" pattern just beneath the glass in one side and a "deep" pattern same distance below the glass on the other. In the experiments reported by Walk \& Gibson (1961) the minimal deep side distance below the glass was $10 \mathrm{in}$. and depths as much as $53 \mathrm{in}$. were used. If the deep side were gradually brought closer to the glass, an "indifference" point should be reached where the animal would descend equally often to shallow and deep sides. Walk and Gibson showed that when both sides of the center board are shallow, or just beneath the glass, hooded rats descend equally often to each side. They also used a one-sided visual cliff where the hooded rat was given a choice of descent or no descent with the visual surface varied in distance below the glass. At 6 in. visual depth only $5 \%$ of the animals descended while $45 \%$ descended to the glass when the pattern was 4 in. below the glass. These results suggest that the indifference point for the hooded rat is somewhere between 0 in. and 6 in. of differential visual depth. "Differential visual depth" means the difference in visual depth between the shallow side ( 0 in. below the glass) and the deep side (usually $10 \mathrm{in}$. or more below the glass, but allowed to approach as close as $1 / 2$ in. below the glass in the present study).

More precise determination of visual depth discrimination is necessary to understand visual depth discrimination capabilities. With 10 in. or more visual depth below the glass on the deep side almost $100 \%$ of most animals tested choose the shallow side. Slight deficiencies in motion perception would not be measured by a very definite visual depth. Determination of the differential visual depth threshold, however, would provide a baseline against which changes could be measured. Sensory deprivation, drugs, and perceptual development are examples of areas where differential threshold depth could be used to understand deficiencies in motion perception even though gross depth perception were unimpaired.

This study reports an apparatus that can be used to measure differential depth thresholds. The apparatus must be lighted from below (unlike the apparatus reported in Walk \& Gibson, 1961, or Walk, 1965). Otherwise, the deep side would be darker than the shallow side because the sides cut off illumination. Illumination cannot be added from the sides when the differential depth is only a few inches. The study also reports the differential visual depth perception threshold for the hooded rat.

Method

The apparatus, shown in Fig. 1, is a modification of the one shown in Walk (1965), Fig. 1, with illumination sources added under both shallow and deep sides and provisions to vary the length of the legs. The $7 \mathrm{ft}$ long boards are $3 / 4 \mathrm{in}$. wide, and 11-1/2 in. high. Two vertical $3 / 4$ in. $x 11-1 / 2$ in. boards 30 in. long are affixed perpendicular and at the center, $18 \mathrm{in}$. apart, to the long boards to provide an $18 \times 30 \mathrm{in}$. box. The floor of the box is of glass (1/8 in. $x 22-1 / 2$ in. $x 32$ in.) on the top groove of a double grooved aluminum piece attached to the bottom of the box.

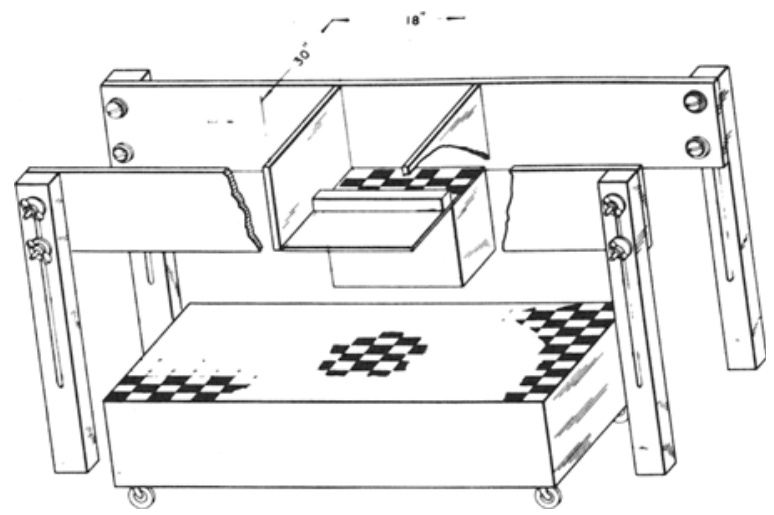

Fig. 1. Schematic diagram of the modified visual cliff apparatus.

The legs of the apparatus are 3-1/2 in. $x 1-1 / 2$ in. $x 36$ in. long with a $1 / 2$ in. groove 12 in. long in them. Wing nuts, washers and bolts attach the legs to the long side of the visual cliff. These permit adjustment in the length of the legs. ${ }^{3}$

The shallow illuminance source is contained in a box 12 in. deep $\times 21-1 / 2$ in. long $\times 14$ in. wide that rides in the bottom groove of the grooved aluminum piece. Two $15 \mathrm{~W}$ standard bulbs are placed on the bottom of it. The top of the box is of Plexiglas W-2447 and a cloth pattern of 1 in. red and white checks is placed on top of the Plexiglas, beneath the glass of the visual cliff. The bottom of the shallow side box is adjustable in depth so that the lights can be brought close or farther to equate illumination on the two sides.

The deep side is a $5 \mathrm{ft} \times 3 \mathrm{ft}$ box $12 \mathrm{in}$. deep, constructed of $1 / 2$ in. plywood, mounted on rollers. Fifteen $W$ bulbs are mounted 1 $\mathrm{ft}$ apart on the floor of the box, three rows of 5 bulbs or 15 in all. The box is covered by $1 / 8$ in. Plexiglas ( 62 in. $x 38$ in.) and a $5 \mathrm{ft}$ $x 3 \mathrm{ft}$ cloth piece of 1 in. red and white checks is placed on top of the Plexiglas. The box is on coasters so that it can be moved from one side to the other.

A center board $3-1 / 2$ in. high $\times 18 \mathrm{in}$. long and 3-3/4 in. wide is placed on top of the glass of the 18 in. $x 30$ in. box, bisecting it into two fieids about 18 in. $x 13-1 / 8$ in.

The lamps are all connected in parallel to insure equal voltage drop across each lamp. Plexiglas was chosen as the translucent material because it gives no "hot" spots. Brightness on each side was equal as measured by taking a direct reading with a Weston Master V light meter, a reading of 7.5 or about $18 \mathrm{ft}-\mathrm{c}$.

The Ss were 92 hooded rats from 22 to 123 days old reared in the laboratory. All animals were experimentally naive.

Table 1

Choices of Hooded Rats with Differential Depth Varied

\begin{tabular}{|c|c|c|c|c|c|c|c|c|}
\hline \multicolumn{2}{|c|}{$\begin{array}{c}\text { Depth } \\
\text { Differential } \\
\text { (inches) }\end{array}$} & \multicolumn{3}{|c|}{ Single Run } & \multicolumn{3}{|c|}{ Single \& Plural Run } & \multirow[b]{2}{*}{ No $\mathrm{Go}$} \\
\hline & $\mathbf{N}$ & Shallow & Deep & No Go & $\mathbf{N}$ & Shallow & Deep & \\
\hline $1 / 2$ & 10 & 5 & 3 & 2 & 10 & 5 & 3 & 2 \\
\hline 1 & 7 & 1 & 4 & 2 & 7 & 1 & 4 & 2 \\
\hline $11 / 2$ & 15 & 7 & 6 & 2 & 47 & 23 & 18 & 6 \\
\hline 2 & 19 & 10 & 7 & 2 & 42 & 20 & 14 & 8 \\
\hline $21 / 2$ & 14 & 7 & 6 & 1 & 45 & 18 & 14 & 13 \\
\hline 3 & 12 & 6 & 3 & 3 & 33 & 17 & 8 & 8 \\
\hline $31 / 2$ & 11 & 8 & 2 & 1 & 11 & 8 & 2 & 1 \\
\hline $41 / 2$ & 4 & 3 & 0 & 1 & 11 & 7 & 1 & 3 \\
\hline $61 / 2$ & & & & & 7 & 4 & 1 & 2 \\
\hline
\end{tabular}




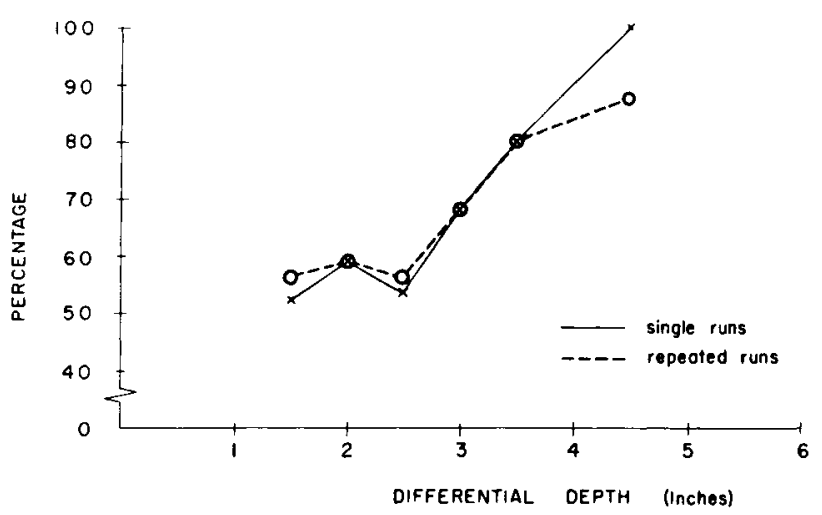

Fig. 2. Per cent descents of Ss run once or more than once at various visual depths.

The legs of the apparatus were adjusted to permit the deep side pattern to vary in visual distance from $1 / 2$ in. to $6-1 / 2$ in. below the glass. The animals were placed on a center board 3-1/2 in. high and allowed $3 \mathrm{~min}$ to descend. Those not descending in $3 \mathrm{~min}$ were scored as "no go." The animals were run more than once, but only once at any visual depth. The position of the deep side was changed (from east to west of the center board or vice versa) after about 5-6 animals were tested. The glass on both sides of the center board was cleaned with a commercial glass cleaner after each trial.

Results

The results are shown in Table 1 and Fig. 2. The hooded rat does not choose the shallow side reliably until at least $3 \mathrm{in.}$ of differential visual depth are available. The split at 3 in. is 17 shallow, 8 deep or $z=1.60, p<.05$ on a one-tailed test. If one wished to be conservative, and use a two-tailed test, the 3 in., $3-1 / 2$ in., and $4-1 / 2$ in. visual depths must be combined and only single run animals used because Ss were run at more than one visual depth. The split for 3 to $4-1 / 2$ in., single run $S$ s, is 17 shallow and 5 deep, $z=2.345, p<.05$ on a two-tailed test. The estimate from Fig. 2 by extrapolating from the $75 \%$ point would be that the differential visual depth threshold for the hooded rat is about $3-1 / 2$ in.

Discussion

This study has shown that the differential visual depth threshold for the hooded rat is about 3-1/2 in. However, research conducted after the preparation of the thesis on which this paper is based found that about $4 \mathrm{in}$. differential visual depth is needed for the hooded rat to choose the shallow side reliably (Walk \& Bond, 1968). This makes the combining of the $3,3-1 / 2$, and $4-1 / 2$ in. depths for a two-tailed test more meaningful since it shows that the more conservative estimate provided results that were much easier to replicate.

We have thus described an apparatus that permits measurement of the differential visual depth perception threshold and we have shown what this threshold in the hooded rat is when the deep side of the visual cliff is about 3-1/2 in. below the shallow side. From such an apparatus one can measure subtle effects on depth perception. For example, Walk \& Bond (1968) used this apparatus to show that hooded rats reared in the dark for 90 days could still discriminate depth at a visual depth of $10 \mathrm{in}$., replicating previous studies, but they were deficient as compared to light-reared controls when the differential visual depth was only 4 in.

\section{REFERENCES}

BOOHER, H. R. Differential visual depth perception threshold in the hooded rat. Unpublished M. A. thesis, George Washington University, 1967.

WALK, R. D. The study of visual depth and distance perception in animals. In D. S. Lehrman, R. A. Hinde, \& E. Shaw (Eds.), Advances in the study of behavior. Vol. 1. New York: Academic Press, 1965, pp. 99-154.

WALK, R. D., \& BOND, E. K. Deficit in depth perception of 90-day-old dark-reared rats. Psychon. Sci., 1968, 10, 383-384.

WALK, R. D., \& GIBSON, E. J. A comparative and analytical study of visual depth perception. Psychol Monogr., 1961, No. 75, 1-44, (Whole No. 519). NOTES

1. Supported in part by a NIH Biomedical Sciences Support Grant to George Washington University. The study is a portion of an unpublished master's thesis by the first author supervised by the second author. The master's thesis (Booher, 1967) gives more details of the apparatus than are presented here.

2. Now at Naval Ordnance Command Hq., Washington, D. C.

3. After this experiment visual depth was altered by placing wooden blocks of various heights under the four legs rather than by adjusting the sliding grooves because such adjustment takes too much time. 